\title{
Dyspnoea perception during clinical remission of atopic asthma
}

\author{
L.M. van den Toorn*\#, S.E. Overbeek", J-B. Prins", H.C. Hoogsteden", J.C. De Jongste*
}

\begin{abstract}
Dyspnoea perception during clinical remission of atopic asthma. L.M. van den Toorn, S.E. Overbeek, J-B. Prins, H.C. Hoogsteden, J.C. De Jongste. (C) ERS Journals Ltd 2002.

ABSTRACT: Symptoms of atopic asthma often disappear around puberty. The authors recently demonstrated that this clinical remission is accompanied with ongoing airways inflammation in most subjects. The discrepancy between lack of symptoms and persistent airway inflammation suggests that perception of the symptoms is unclear. In the present study, young adults in clinical remission of atopic asthma assigned themselves a modified Borg score during methacholine and adenosine-5'-monophosphate induced bronchoconstriction. Borg scores of subjects in clinical remission were compared with those of symptomatic asthmatic subjects. A marked variation in the Borg scores at a $20 \%$ fall in the forced expiratory volume in one second was found. Significant differences in Borg scores between remission patients and asthmatics could not be detected.

It was concluded that perception of dyspnoea, induced with methacholine and adenosine challenge, is similar in young adults in clinical remission of atopic asthma compared to that of patients with symptomatic asthma. Hence, an unclear perception seems to be an unlikely explanation for the discrepancy between lack of symptoms and ongoing inflammation. Other factors, including both physical and psychological ones, may play a role in the apparent absence of symptoms, thereby potentially leading to undertreatment.
\end{abstract}

Eur Respir J 2002; 19: 1047-1050.
Depts of *Paediatrics/Paediatric Respiratory Medicine and ${ }^{\#}$ Pulmonary Medicine, Erasmus University Medical Centre, Rotterdam, the Netherlands.

Correspondence: L.M. van den Toorn, Dept of Pulmonary Medicine, Erasmus University Medical Centre, Dr Molewaterplein 50, $3015 \mathrm{GE}$ Rotterdam, The Netherlands.

Fax: 31104089453

E-mail: L.vandentoorn@planet.nl

Keywords: Asthma, Borg, dyspnoea, perception, remission, symptoms

Received: September 292001

Accepted after revision January 17 2002

This study was supported by grant 96.20 from the Netherlands Asthma Foundation.
In asthma, symptoms often decrease or even seem to disappear around puberty. Unfortunately, clinical remission is followed by a relapse later in life in a considerable proportion of subjects $[1,2]$. The authors recently found ongoing airways inflammation during clinical remission of atopic asthma [3, 4]. Persistent airways inflammation during clinical remission would possibly explain the high relapse rate. The relationship between dyspnoea perception and other indices of asthmatic severity, such as the degree of bronchoconstriction, is poor $[5,6]$. Conversely, impaired dyspnoea perception is especially believed to play a role in severe asthma [7-9]. Poor perception of airflow obstruction may lead to undertreatment of asthma [10]. Especially in view of the high relapse rate of asthma later in life, diminished perception of dyspnoea in subjects in clinical remission of asthma is of great clinical relevance. Therefore, the hypothesis of the present study was that subjects in clinical remission of atopic asthma have blunted perception of dyspnoea. Dyspnoea scores, including visual analogue scale (VAS) scores and (modified) Borg scores, can be assessed during spontaneous asthma or during induced bronchoconstriction [11]. The aim of the present study was to compare dyspnoea scores during induced bronchoconstriction between young adults in clinical remission of asthma and currently symptomatic asthmatic subjects. Since the mechanism of bronchoconstriction differs between direct stimuli (methacholine $(\mathrm{MCh})$ ) and indirect stimuli (adenosine monophosphate (AMP)), and may give rise to a different perception, MCh as well as AMP challenges were used in both groups.

\section{Subjects, materials and methods}

\section{Subjects}

Young adults with atopic asthma, aged 18-25 yrs, were selected from the Sophia Children's Hospital (Rotterdam, the Netherlands) discharged patients files. Clinical remission of atopic asthma was defined as reported complete absence of cough, wheezing and breathlessness at rest and on exertion in subjects not taking any asthma medication for at least 12 months prior to the study. Approximately $80 \%$ of subjects in clinical remission showed elevated nitric oxide levels, eosinophilic airway inflammation, and hyperresponsiveness to both MCh and AMP [3, 4]. All subjects responding with a $20 \%$ fall in the forced expiratory volume in one second (FEV1) during induced bronchoconstriction with MCh or AMP were considered eligible for the present study. Ten eligible subjects in remission were included, and compared with 10 patients with asthma who had persistent symptoms, assessed with the short-form (SF)-36 health survey quality of life/symptom score form, at 
least once a month in the year preceding the study, and used inhaled $\beta_{2}$-agonists on demand in order to relieve symptoms. Subjects with current asthma could thus be defined as having "mild persistent asthma" according to global initiative for asthma (GINA) guidelines. All subjects had a history of wheezing and chest tightness and were previously diagnosed as having asthma according to American Thoracic Society (ATS) criteria [12]. All were atopic defined as radio allergosorbent test (RAST) class 2 or higher for at least one common airborne allergen. All subjects were lifelong nonsmokers in a stable clinical condition and did not take inhaled steroids, including nasal steroids, or anti-allergic medication like cromoglycate and antihistamines for at least $1 \mathrm{yr}$ prior to the study.

Common exclusion criteria were an inability to perform lung function tests reproducibly, and illnesses that may have affected lung function. None of the subjects in the study reported symptoms of respiratory infection in the month prior to the study.

The study was approved by the Medical Ethics Committee of the Erasmus University Medical Centre, Rotterdam (the Netherlands).

\section{Study design}

A cross-sectional study with two visits on separate days was performed. At the first visit, subjects gave informed written consent and were asked about their asthmatic symptoms, history and requirement of rescue medication during the past year. Also, physical examination was performed, followed by determination of $\mathrm{MCh}$ responsiveness. At the second visit, scheduled at least 1 day after visit one, subjects underwent an AMP challenge test. During the tests, subjects were asked to score their degree of breathlessness after each given dose according to a modified Borg scale. The sequence and intervals of the provocation tests were chosen in order to avoid any influence of the AMP challenge on MCh responsiveness [13].

\section{Methacholine and adenosine-5'-monophosphate challenge}

Challenge tests were performed at the same time of day $( \pm 1 \mathrm{~h})$ according to the dosimeter method as described in detail earlier [3, 14]. Short-acting $\beta_{2}$-agonists were not allowed within $8 \mathrm{~h}$ prior to the test. If a patient responded to saline or the lowest concentration of either MCh or AMP, they were assigned a provocative dose causing a $20 \%$ fall in the FEV1 (PD20) value of half the starting dose. Inhalation provocation tests were performed using doubling concentrations of $0.15-78.4 \mathrm{mg} \cdot \mathrm{mL}^{-1} \mathrm{MCh}$ bromide in phosphate-buffered saline or $0.08-160 \mathrm{mg} \cdot \mathrm{mL}^{-1}$ AMP in normal saline (Sigma Chemical Co., St. Louis, MO, USA). During MCh and AMP challenge, before each FEV1 measurement, perception of dyspnoea was assessed on a modified Borg scale. A perception score at a $20 \%$ fall in FEV1 (PS20) was obtained by interpolation of the two last points on the perception/fall in FEV1 curve [10].

\section{Statistical analysis}

Data are expressed as mean PS20 \pm SEM. Comparisons between groups were made by an unpaired t-test. A two-tailed p-value of $<0.05$ was considered significant. Correlation was expressed as a partial correlation coefficient.

\section{Results}

Twenty subjects could be assigned both a PS20 MCh value and a PS20 AMP value (10 subjects with currently symptomatic atopic asthma and 10 subjects in clinical remission of asthma). The subject characteristics are summarized in table 1. The two groups were comparable with respect to age, FEV1 and PD20 AMP. PD20 MCh in currently symptomatic asthmatic subjects was significantly lower than in subjects in clinical remission $(\mathrm{p}=0.034)$.

All subjects, including the ones in clinical remission, experienced some degree of dyspnoea at reaching a $20 \%$ decrease in FEV1, even though there was a marked within-group variation in PS20 (for instance $0.5-9$ in the remission group with respect to $\mathrm{MCh}$ provocation). Nevertheless, for both inhaled stimuli no significant difference between currently asthmatic subjects and subjects in clinical remission with respect to PS20 could be detected (figs. 1 and 2).

Mean PS20 MCh was $2.7 \pm 1.1$ (range 1-4) and $3.2 \pm 2.5$ (range 0.5-9) for currently asthmatic subjects and subjects in remission, respectively, and $3.3 \pm 1.3$ (range $1-5$ ) versus $3.7 \pm 1.9$ (range $0.5-6$ ) with respect to AMP-induced bronchoconstriction. The authors did not find a significant relationship between bronchial responsiveness, expressed as PD20, and respiratory distress at reaching a $20 \%$ decrease in FEV1 for both inhaled stimuli $(r=0.23$ and $p=0.34$ for MCh; $r=0.06$ and $\mathrm{p}=0.81$ for AMP; figs. 3 and 4).

\section{Discussion}

In this study no significant difference in dyspnoea perception between currently asthmatic subjects and subjects in clinical remission of atopic asthma at $20 \%$ fall in FEV1 with MCh and AMP-induced bronchoconstriction was found. $\mathrm{MCh}$ responsiveness differed

Table 1. - Subject characteristics

Asthmatic subjects Remission subjects

\begin{tabular}{|c|c|c|}
\hline Subjects $n$ & 10 & 10 \\
\hline Age yrs & $22.5 \pm 0.5(19-25)$ & $20.6 \pm 0.6(19-24)$ \\
\hline Sex M:F & $7: 3$ & 10:0 \\
\hline FEV $1 \mathrm{~L} \cdot \mathrm{min}^{-1}$ & $90 \pm 3(80-106)$ & $91 \pm 4(63-107)$ \\
\hline $\mathrm{PD} 20 \mathrm{MCh} \mu \mathrm{mol}$ & $0.4 \pm 0.3(0.1-2.8)$ & $2.3 \pm 1.1(0.1-9.9)$ \\
\hline PD20 AMP $\mu \mathrm{mol}$ & $5.3 \pm 2.3(0.6-27.3)$ & $9.8 \pm 2.6(1.0-22.2)$ \\
\hline
\end{tabular}

Age and forced expiratory volume in one second (FEV1) are presented as mean \pm SEM (range) and the provocative dose causing a $20 \%$ fall in the FEV1 (PD20) as median \pm SEM (range). MCh: methacholine; AMP: adenosine monophosphate; M: male; F: female. 


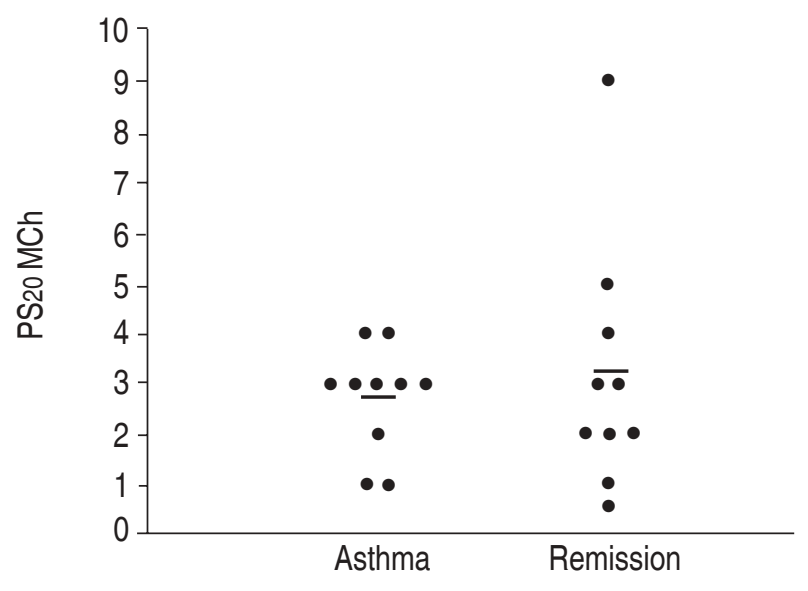

Fig. 1.-Borg scores at a $20 \%$ fall in the forced expiratory volume in one second $(\mathrm{FEV} 1)$ during methacholine $(\mathrm{MCh})$ challenge in subjects in clinical remission of atopic asthma and currently asthmatic subjects. PS20: a perception score at a $20 \%$ fall in FEV1. $\mathrm{n}=10$. Horizontal bars represent mean values.

significantly between subjects in remission and currently symptomatic asthmatics, whereas AMP responsiveness did not. All subjects experienced some degree of dyspnoea at reaching a 20\% fall in FEV1. Dyspnoea scores varied from "very slight dyspnoea" to "almost extreme dyspnoea". A significant correlation between dyspnoea perception and degree of bronchial hyperresponsiveness could not be detected.

The finding that $\mathrm{MCh}-$, but not AMP responsiveness differs significantly between subjects in clinical remission and currently asthmatic subjects, can be explained by differences in the mechanism of action. Where MCh responsiveness may be influenced by structural changes in the airways and active airway inflammation, AMP is believed to reflect only active airway inflammation, including an increased number of mast cells. Thus, since currently asthmatic subjects may suffer from both more pronounced structural changes and more active inflammation, as compared

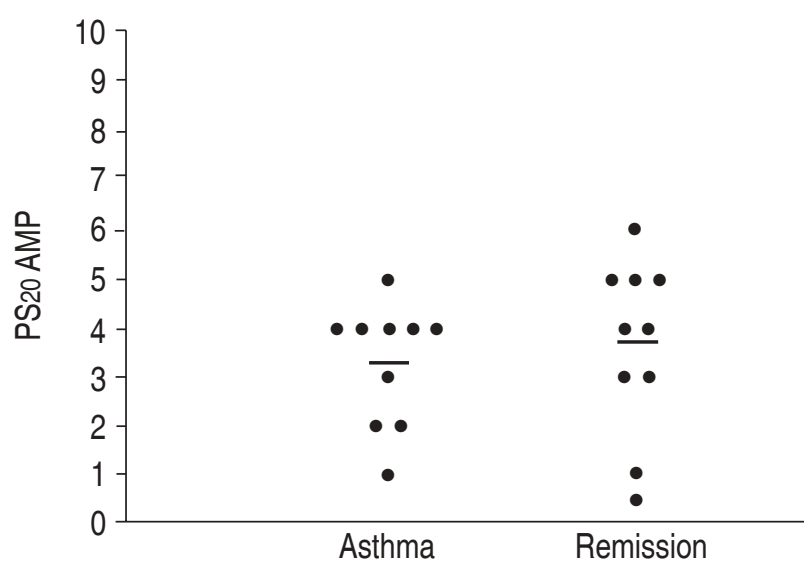

Fig. 2.-Borg scores at a $20 \%$ fall in the forced expiratory volume in one second $\left(\mathrm{FEV}_{1}\right)$ during adenosine monophosphate (AMP) challenge in subjects in clinical remission of atopic asthma and currently asthmatic subjects. PS20: a perception score at a $20 \%$ fall in FEV1. $\mathrm{n}=10$. Horizontal bars represent mean values.

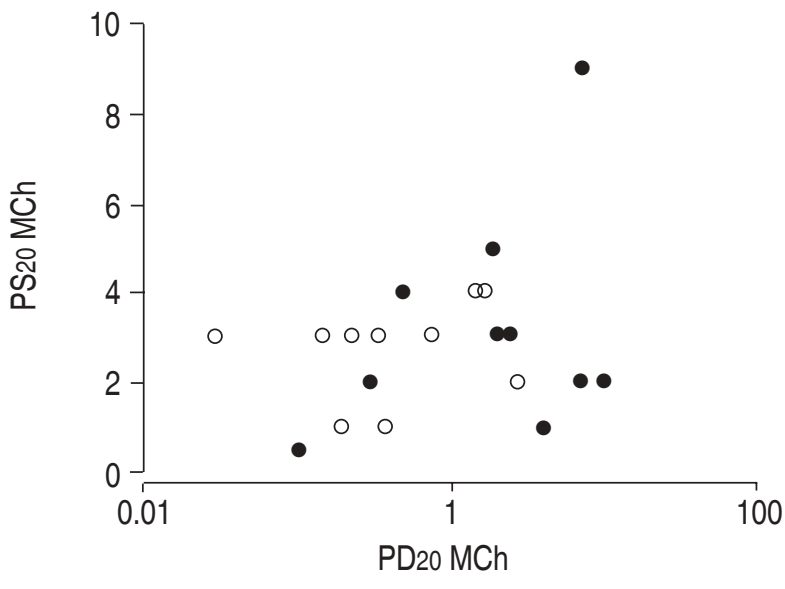

Fig. 3. - Partial correlation coefficients between a provocative dose causing a $20 \%$ fall in the forced expiratory volume in one second (FEV1) (PD20) and a perception score at a $20 \%$ fall in FEV 1 (PS20) with respect to methacholine (MCh) challenge in subjects in clinical remission of atopic asthma and currently asthmatic subjects. $\bigcirc$ : asthma; $\bigcirc$ : remission. $r=0.23 ; p=0.34$.

with subjects in remission, MCh responsiveness may separate the groups better than AMP responsiveness.

In 1994, Boulet et al. [15] suggested that a lack of symptoms may be an insufficient tool for determining whether asthma is in true remission. Indeed, there is a weak correlation between symptoms on the one hand and bronchial hyperresponsiveness and airways inflammation on the other. Several investigators have highlighted the possibility of diminished perception of dyspnoea in subjects with more severe grades of asthma, potentially leading to undertreatment in these subjects [7-9]. Such an inverse relationship is not a consistent finding [10]. In the present study there was no correlation between dyspnoea perception and PD20. The study population, however, had a limited range of asthma severity.

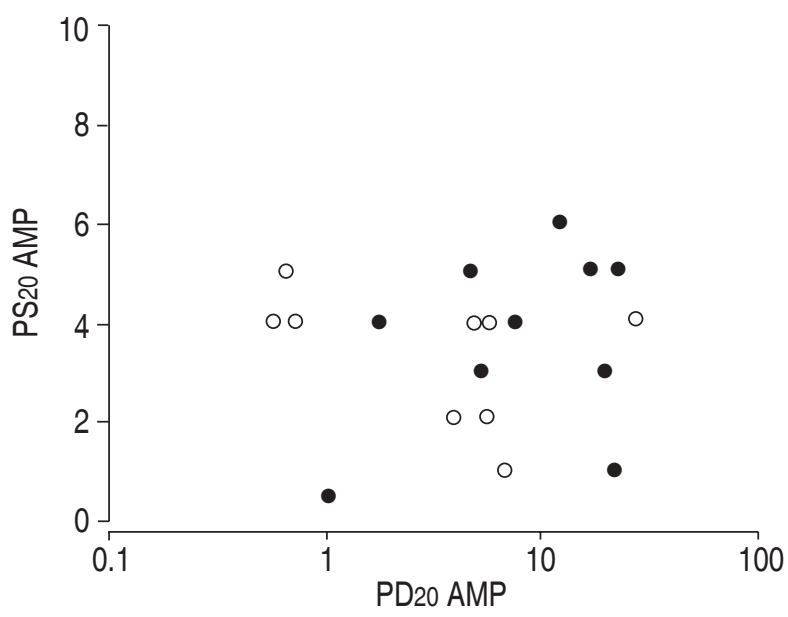

Fig. 4. - Partial correlation coefficients between a provocative dose causing a $20 \%$ fall in the forced expiratory volume in one second (FEV1) (PD20) and a perception score at a $20 \%$ fall in FEV 1 (PS20) with respect to adenosine monophosphate (AMP) challenge in subjects in clinical remission of atopic asthma and currently asthmatic subjects. $\bigcirc$ : asthma; $\bigcirc$ : remission. $r=0.06 ; \mathrm{p}=0.81$. 
Reduced dyspnoea perception, during clinical remission, could possibly explain the absence of symptoms despite persistent airways inflammation and bronchial hyperresponsiveness [4] found in these subjects. Studies concerning symptom perception in asymptomatic asthmatics are scarce. In the present study subjects in clinical remission of atopic asthma supposedly having no grade of asthma at all were included. Given the ongoing airways inflammation the authors recently documented in a considerable proportion of these subjects [3, 4], it was very important to show whether a diminished perception of symptoms was present. The results of the present study did not confirm that an unclear symptom perception explains the lack of symptoms. Subjects in clinical remission are obviously capable of detecting airway narrowing at a similar level to currently asthmatic subjects. Conversely, others found a poor relationship between perception of spontaneous "daily life" asthma and artificially-induced bronchoconstriction $[10,11]$. Therefore, the possibility that this is also true for subjects in clinical remission of asthma cannot be excluded. Thus, it might still be possible that as a result of biomechanical, pathophysiological or psychological factors, abnormal daily-life fluctuations in airflow are not interpreted as asthma by subjects in clinical remission $[6,16]$. A fast decline in FEV1 as a result of MCh- or AMP-induced bronchoconstriction is probably less prone to interindividual differences, and could thus explain the present findings. Nevertheless, since dyspnoea and other asthmatic symptoms seem to be an interplay between the degree of asthmatic inflammation and many other influences including physical and psychological factors [6,7], it is suggested that the absence of asthmatic symptoms in subjects regarded as ex-asthmatics should be interpreted with great care.

To conclude, the study indicates that the lack of symptoms, despite persistent bronchial hyperresponsiveness and ongoing airways inflammation, during clinical remission of asthma is not due to an unclear symptom perception. Other factors, which include physical and psychological ones, may play a role in the apparent absence of symptoms in daily life. This is a potential factor leading to undertreatment.

\section{References}

1. Barbee RA, Murphy S. The natural history of asthma. J Allergy Clin Immunol 1998; 102: S65-S72.

2. Panhuysen CI, Vonk JM, Koeter GH, et al. Adult patients may outgrow their asthma: a 25-year follow-up study. Am J Respir Crit Care Med 1997; 155: 12671272.

3. Van den Toorn LM, Prins JB, Overbeek SE, Hoogsteden HC, de Jongste JC. Adolescents in clinical remission of atopic asthma have elevated exhaled nitric oxide levels and bronchial hyperresponsiveness. Am J Respir Crit Care Med 2000; 162: 953-957.

4. Van den Toorn LM, Overbeek SE, De Jongste JC, Leman K, Hoogsteden HC, Prins J-B. Airways inflammation is present during clinical remission of atopic asthma. Am J Respir Crit Care Med 2001; 164: 2107-2113.

5. Teeter JG, Bleecker ER. Relationship between airway obstruction and respiratory symptoms in adult asthmatics. Chest 1998; 113: 272-277.

6. Rietveld S. Symptom perception in asthma: a multidisciplinary review. J Asthma 1998; 35: 137-146.

7. Chetta A, Gerra G, Foresi A, et al. Personality profiles and breathlessness perception in outpatients with different gradings of asthma. Am J Respir Crit Care Med 1998; 157: 116-122.

8. Veen JC, Smits HH, Ravensberg AJ, Hiemstra PS, Sterk PJ, Bel EH. Impaired perception of dyspnea in patients with severe asthma. Relation to sputum eosinophils. Am J Respir Crit Care Med 1998; 158: 1134-1141.

9. Bijl-Hofland ID, Cloosterman SG, Folgering HT, Akkermans RP, van Schayck CP. Relation of the perception of airway obstruction to the severity of asthma. Thorax 1999; 54: 15-19.

10. Boulet LP, Leblanc P, Turcotte H. Perception scoring of induced bronchoconstriction as an index of awareness of asthma symptoms. Chest 1994; 105: 14301433.

11. Boudreau D, Styhler A, Gray-Donald K, Martin JG. A comparison of breathlessness during spontaneous asthma and histamine- induced bronchoconstriction. Clin Invest Med 1995; 18: 25-32.

12. Standards for the diagnosis and care of patients with chronic obstructive pulmonary disease (COPD) and asthma. Am Rev Respir Dis 1987; 136: 225-244.

13. Rosati G, Hargreave FE, Ramsdale EH. Inhalation of adenosine 5'-monophosphate increases methacholine airway responsiveness. J Appl Physiol 1989; 67: 792796.

14. Birnie D, thoe Schwartzenberg GW, Hop WC, van Essen-Zandvliet EE, Kerrebijn KF. Does the outcome of the tidal breathing and dosimeter methods of assessing bronchial responsiveness in children with asthma depend on age? Thorax 1990; 45: 199-202.

15. Boulet LP, Turcotte H, Brochu A. Persistence of airway obstruction and hyperresponsiveness in subjects with asthma remission. Chest 1994; 105: 1024-1031.

16. Salome CM, Xuan W, Gray EJ, Belooussova E, Peat JK. Perception of airway narrowing in a general population sample. Eur Respir J 1997; 10: 1052-1058. 